\title{
Encouraging children to produce rhythmic beat gestures leads to better narrative discourse performances
}

\author{
Ingrid Vilà-Giménez ${ }^{1}$, Pilar Prieto ${ }^{2,1}$ \\ ${ }^{1}$ Department of Translation and Language Sciences, Universitat Pompeu Fabra, Catalonia \\ ${ }^{2}$ Institució Catalana de Recerca i Estudis Avançats, ICREA, Catalonia \\ ingrid.vila@upf.edu, pilar.prieto@upf.edu
}

\begin{abstract}
Recent research has shown that when preschoolers listen to a speaker who is simultaneously making beat gestures, this favors their recall and comprehension of what they have heard and also boosts their narrative performance. However, previous studies have not tested the effect of encouraging children to produce beat gestures while retelling narrativesas opposed to merely observing them-on their narrative performances. In this study, a total of 47 five- and six-year-old children participated in a between-subjects brief training study experiment with a pretest and an immediate posttest design. Children were exposed to a training phase with a total of six one-minute stories, presented under two experimental conditions: 1) beat non-encouraging condition, and 2) beat encouraging condition. Video recordings of the pretest and posttest narratives were then scored for narrative structure and fluency. A comparison of scores showed that children in the group that had been encouraged to use beat gestures performed better than the group of children who were simply asked to retell the story without gesture instruction. All in all, this evidence suggests that encouraging the use of beat gestures by children helps to boost their subsequent narrative performance.
\end{abstract}

Index Terms: beat gestures, narrative discourse performance, between-subjects training study

\section{Introduction}

Narratives are a solid measure of children's more complex language skills $[1,2,3,4,5,6,7]$, and later school literacy success can be predicted by narrative ability measures [8]. While the period from age 3 to 6 constitutes "a particularly relevant age range to observe children's burgeoning narrative abilities in gesture and speech" [7, p. 1021], it is only around age 5 or 6 that children begin to produce 'true narratives' in which all the important features of a well-produced narrative are involved in the discourse [9].

Research on narrative development has shown that children's use of representational gestures benefits their narrative abilities $[2,6,7]$. In fact, as Colletta et al. [10] point out, gesture and speech go hand in hand: children's use of gestures related to narrative organization becomes more developed as children's narratives become more complex. In general, research on child language has tended to focus on the effects of both observing and producing representational gestures (also called iconic and metaphoric gestures, i.e., those which represent referential properties of objects and concepts; see [11]) on cognitive and language development (e.g., [12]).
However, so far little attention has been devoted to the role of another type of gesture, namely beat gestures, which are defined as rhythmic hand movements typically associated with prosodic prominence in speech that do not reflect contextual meaning but rather mark informational focus (see [11]). Though there is mixed evidence regarding the benefits of observing beat gestures for preschool children (e.g., [13]), a number of studies have demonstrated that observing beat gestures significantly enhances children's memory recall in a pragmatic discourse context $[14,15,16]$. To our knowledge, there are only three studies specifically focusing on the effects of observing beat gestures on narrative development. One, by Macoun and Sweller [17], found that observing beat gestures conferred no benefit for narrative recall and comprehension in children. The other two, however, detected positive effects in children when they heard stories in which beat gestures were aligned with prosodic prominences. Llanes-Coromina et al. [16] found that children's narrative comprehension improved under these conditions, and Vilà-Giménez et al. [1] showed that preliminary training of this sort led 5- and 6-year olds to produce better narrative performances (i.e., they achieved higher narrative structure scores).

While these studies looked at the effect of observing gestures, other work has examined the impact of not just observing but also performing gestures. Though some studies conclude otherwise (see $[18,19]$ for overviews), the dominant assumption in the literature is that gesturing has positive effects on various cognitive domains. First, gesturing can help people generate problem-solving strategies in mathematics $[20,21,22,23]$ or other thinking tasks $[24,25]$. The use of spoken explanations with correlated co-speech gestures in problem-solving tasks also leads children to understand notions that are not expressively conveyed in speech (see [26] for a review). In terms of development, forcing children to gesture while explaining problem-solving strategies to math problems seems to provide them with new and correct solution strategies expressed in gesture in which they had not turned to before [22]. Other authors have demonstrated that when 8- to 11-year-old children spontaneously produced gestures or were prompted to do so, they came up with creative novel uses for everyday items, suggesting that the gestures helped them to both think and create ideas more fluently [27]. Finally, one study found that producing gestures (beat gestures, in this case) facilitated lexical access in adults [28].

The aim of the current study is to test whether encouraging the production of beat gestures through a brief training session will improve 5- to 6-year-old children's narrative discourse performance in terms of narrative structure and fluency scores, compared to just observing beat gestures. We hypothesize that it will, given the evidence that beat gestures play an important 
role as highlighters of linguistic functions $[29,30]$ such as focus marking, rhythmic marking, and discourse structure marking. Thus, we suggest that beats are pragmatically meaningful gestures $[11,31,32]$ that can help build up children's narrative performance.

\section{Methods}

The experiment consisted of a between-subjects brief training study with a pretest and an immediate posttest design.

\subsection{Participants}

Fifty-three children (23 boys and 30 girls) from the Girona area of Catalonia participated in this study. The majority of the participants $(n=49)$ were drawn from two schools (Col-legi Dr. Masmitjà and Escola Montjuïc); the four remaining children were recruited individually. Data from six of the original participants had to be excluded from analysis either because of technical recording problems $(n=4)$ or because they did not engage in the experimental task $(n=2)$. Thus, the dataset analyzed in this study came from the remaining 47 participants (mean age $=5.92 ; S D=0.54$ ). Parental consent was obtained before the experiment. Based on family questionnaires [33], all the participants were typically developing children with no prior history of communication disorders in themselves or within their families. Although Catalan-Spanish bilingualism is not unusual in this community, average daily exposure to Catalan among these children was found to be $88.74 \%(S D=10.68)$.

\subsection{Materials}

The pretest, training, and posttest materials used in the experiment were the same as those used in [1]. Pretest and posttest consisted of the children retelling what they had seen in four short $(\sim 41-50 \mathrm{~s})$ animated cartoons about a small mouse and his friends (Westdeutscher Rundfunk Köln, http://www.wdrmaus.de, [2, 34]), which were previously unfamiliar to the children. The video clips contained only background music, without any speech. Two of these cartoons were shown in the pretest and two different ones in the posttest (the first one always featuring one character, whereas the second one always featuring two). All these cartoons followed the same goal-based structure, which includes the following main features of a narrative: a) temporal and causal structure, b) animate protagonists, c) an initiating event, d) one goal, e) an attempt to achieve the goal, and f) an outcome or resolution (e.g., $[2,6])$.

The training materials consisted of 12 video-recorded short narratives performed in Catalan by two adult female storytellers ( 6 stories $\times 2$ storytellers). All the narratives were about different animals that lived on a farm and followed a similar structure as the animated cartoons. (These videos were the same ones used in [1], except that only those performed with beat gestures were used in this study.) The two storytellers were asked to use child-directed speech with a smiling face, as if they were speaking to a group of children. The beat gestures used in the training stories highlighted discourse markers and focal content words. According to previous preliminary studies ran before recording the stimulus materials (see [1]), palm-up outward hand movements were the beat gestures used to emphasize discourse markers, whereas inward hand movements were used to emphasize focal content words. Both storytellers were monitored for consistency in synchronizing their beat gestures with corresponding target items (see [1] for more details).

Eight different versions of a PowerPoint presentation were prepared in which the order of the pretest and posttest cartoons, the six training stories, and the two storytellers were counterbalanced.

\subsection{Procedure}

The experiment followed the same pretest-training-posttest procedure as in [1] (see Figure 1). Each participant was tested individually in a quiet classroom at their school and was videotaped in all phases of the task. Children were randomly assigned to one of two conditions, beat non-encouraging ( $n=$ $25)$ or beat encouraging $(n=22)$ (see 2.3.2 below). The whole session lasted approximately 30 minutes.

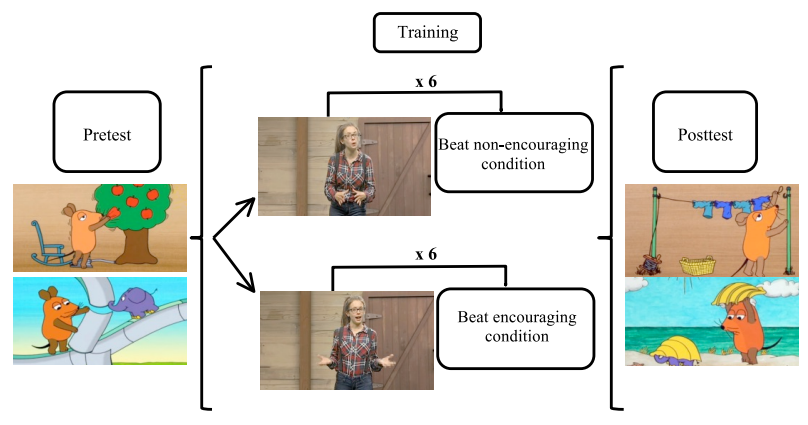

Figure 1: Experimental procedure.

\subsubsection{Pretest and Posttest}

The pretest and posttest phases consisted of a narrative task which was conducted identically as in [1]. The child first watched a cartoon using a laptop equipped with headphones and was then asked to recount what $\mathrm{s}$ /he had seen to the experimenter, who, though present in the room, pretended not to have watched the video clip. To provide motivation, the narrative task was carried out like a game, as the experimenter had to guess the story that the child was retelling through a variety of pictures, always giving positive feedback to the child. Additional neutral prompts (e.g., "Can you tell me the story?" or "Anything else?") were asked to the child in order to elicit information if $\mathrm{s} / \mathrm{he}$ did not respond quickly. The retelling finished when the child stopped or had nothing more to say. This procedure was then repeated, using a different cartoon. Though the procedure for pretest and posttest were identical, the two cartoons shown in the pretest were different from the two shown in the posttest.

\subsubsection{Training session}

The training session took place between the pretest and the posttest phases and formed part of the same PowerPoint presentation. Training consisted of watching six videotapes with headphones. In each video, a storyteller told a story while using beat gestures to emphasize discourse markers and focal content words. All participants were shown the same six stories but in different orders of story and storyteller. Prior to viewing, each child was instructed to pay close attention to how the storyteller was moving her hands (e.g., "Look at the 
farmer [the storyteller], see how she moves her hands when she is telling you the story"). After viewing, the child was given different instructions depending on the experimental group to which s/he had been assigned. Those assigned to the beat non-encouraging condition were merely asked to retell the story they had just heard without receiving any gesture instructions.

By contrast, those assigned to the beat encouraging condition were asked to retell the six stories while producing hand movements like those they had seen the storyteller using (see Figure 2). Instructions were along the lines of ("Did you notice that the farmer [the storyteller] moved her hands a lot as she told the story? So now tell me the story just like the farmer did, moving your hands a lot the entire time. Do you remember how she did it? Do you remember when she said, 'Once upon a time, there was a duck...'?'). In this way the experimenter stressed the fact that the farmer moved her hands during the entire narrative. Moreover, whenever the experimenter prompted by means of a quote like this, she modeled the beat gestures the storyteller had used to emphasize discourse markers ("once upon a time") and target words ("a duck").

In order to assess the children's gestural behavior during the narrative training in both conditions, as well as to check the children correctly understood the instructions, the narratives produced during the training were coded for number of gestures used. As expected, the mean production of gestures produced by each child was much higher in the beat encouraging condition $(n=581 ; M=26.41)$ than in the beat non-encouraging condition $(n=55 ; M=2.2)$. No participants were excluded from the dataset due to a lack of instruction understanding.

\section{Beat non-encouraging condition}
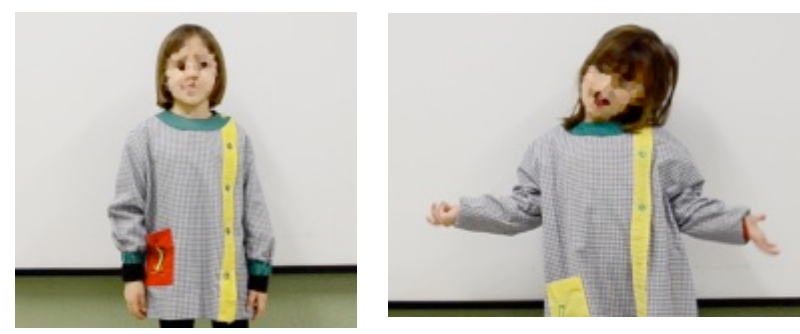

Figure 2: Still images of children performing posttest narratives.

\subsection{Coding system}

The resulting video-recordings of child participants producing narratives during the pretest and posttest (47 children $\times(2$ pretest +2 posttest) $=188$ narratives) were examined and blindly scored by the first author (native speaker of Catalan) for narrative structure and narrative fluency.

\subsubsection{Narrative structure}

For the overall narrative structure scores of the pretest and posttest narratives, we used the same narrative assessmentcoding scheme as in [1], which was adapted from [2,6] and based on [35]. Four main features were considered when analyzing the structure of each story: a) the presence of an animate protagonist, b) its temporal structure, c) its causal structure, and d) the presence of a goal-directed action (i.e., an action including an initiating event, the goal, the attempt to achieve the goal, and the outcome of that attempt) (see [1] for a detailed rubric for scoring child-produced retelling narratives). This yielded a score between 0 and 6 , where the maximum score of 6 corresponded to a complex "complete goal-based narrative" which contained all the above features.

\subsubsection{Fluency}

To rate fluency, we followed the lead of most other studies and had native listeners judge the fluency of the children's productions based on the Likert scale ([36] and see [37, 38] for examples). Unlike the scale used in [1], however, fluency scores were exclusively based on a perceptive coding, with $1=$ extremely disfluent and $7=$ extremely fluent.

\subsection{Statistical analyses}

Two GLMMs [39] were run using SPSS Statistics 23.0 (SPSS Inc., Chicago IL) with overall narrative structure scores and overall fluency scores as two different dependent variables.

In the two GLMM analyses, Training Condition (two levels: beat non-encouraging and beat encouraging) and Test (two levels: pretest and posttest), and the interaction Condition $\times$ Test were set as fixed factors. Subject and Item (i.e., the four stories used in the pretest and posttest) were set as random factors. Bonferroni pairwise comparison post hoc tests were carried out to detect significant main effects and interactions in each of the analyses.

Furthermore, in the GLMM analysis of the fluency scores, Duration was also included as a random factor, as we assume that how long a child can speak correlates with his/her fluency.

\section{Results}

\subsection{Narrative structure scores}

The results of the GLMM analysis indicated a main effect of Test $(F(1,184)=25.194, p=.000)$, showing better narrative structure scores in the posttest than in pretest $(p=.000)$ for all subjects and a significant interaction between Condition and Test $(F(1,184)=6.167, p=.014)$, indicating that narrative structure scores differed depending on the experimental group and whether the narrative was pretest or posttest. Further post hoc analyses showed that the two experimental groups differed significantly $(p=.009)$ in posttest narrative structure scores, with children in the beat-encouraging group producing better narrative structures. Unsurprisingly, pretest score between the two groups did not differ significantly $(p=.628)$, nor did pretest and posttest scores for the beat nonencouraging group $(p=.069)$. However, significant differences $(p=.000)$ were found between pretest and posttest scores in the beat encouraging condition, with better scores in the posttest than in the pretest. Therefore, children performed better in their posttest narratives when they were encouraged to gesture than when they were not (see Figure 3). 


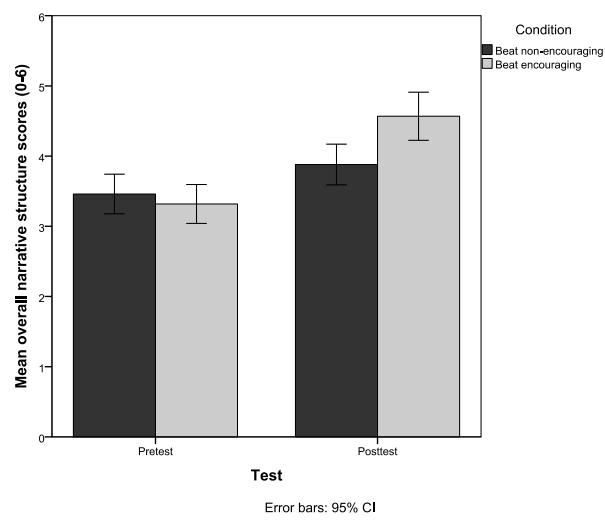

Figure 3: Mean overall narrative structure scores from 0 to 6 , broken down by training condition (beat nonencouraging vs. beat encouraging) and test (pretest vs. posttest). Error bars represent $95 \%$ confidence intervals of the means.

\subsection{Fluency scores}

The results of the GLMM analysis showed a main effect of Test $(F(1,184)=18.277, p=.000)$, with better fluency scores in the posttest than in the pretest $(p=.000)$ and a significant interaction between Condition and Test $(F(1,184)=4.649, p$ $=.032)$. Again, pretest scores were not significantly different across groups. However, whereas pretest and posttest scores for the beat non-encouraging condition did not significantly differ $(p=.112)$, significant differences $(p=.000)$ were found between pretest and posttest scores for the beat encouraging condition, with better fluency scores in the posttest than in the pretest. Therefore, children performed the posttest narratives more fluently when they were encouraged to gesture than when they were not (see Figure 4).

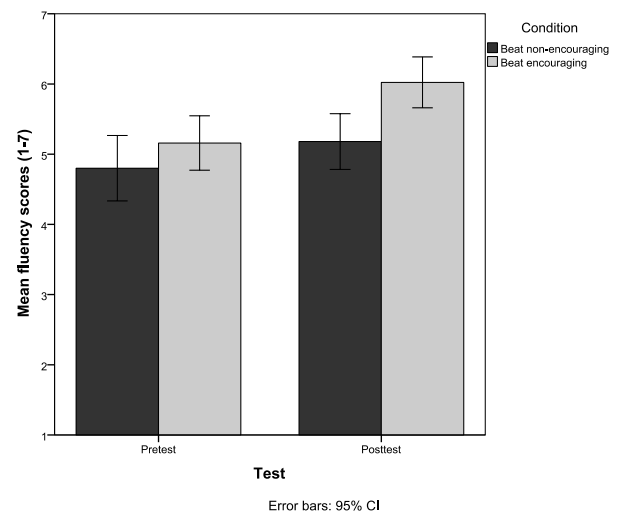

Figure 4: Mean overall fluency scores from 1 to 7 , broken down by training condition (beat non-encouraging $v$ s. beat encouraging) and test (pretest vs. posttest). Error bars represent $95 \%$ confidence intervals of the means.

\section{Discussion and Conclusions}

While previous research in the field of gesture has dealt with the use of representational gestures and their role in boosting narrative development (e.g., [6, 7]), less is known about the potential effects of the production of beat gestures. The aim of the present study was to test whether encouraging 5- to 6-yearold children to perform beat gestures while retelling stories in a brief narrative discourse training task might help them to produce better posttest narrative performances as measured in terms of structure and fluency. Our study is the first one to demonstrate that a short training session featuring narratives produced with beat gestures that prompts beat gesture production in children can have an immediate positive effect on children's narrative structure and fluency scores.

As we initially hypothesized, the results of the current study revealed that children who were encouraged to produce beat gestures performed better-structured and more fluent posttest narratives than children who were just asked to retell the stories without any gesture instruction. Our findings add to the existing literature a clear indication of the usefulness of not only observing [as in 1] but also producing beat gestures in a brief narrative discourse training. This constitutes further evidence that beat gestures serve as visual highlighters of linguistic functions that are associated with focus marking, rhythmic marking, and discourse structure marking [29, 30], confirming electrophysiological studies showing that beats are connected to language-related areas of the brain (e.g., [40]).

The present findings have educational implications. Though there have been mixed results with regard to the benefits of teachers using co-speech gestures [18, 19], we strongly believe that gesturing and specifically the use of beat gestures can play an important role in fostering language development (see [26] for a review). However, it would be of interest to test for long-term effects of this beat-accompanied retelling technique and also to explore the effect of longer training periods.

In conclusion, the combination of observing and producing beat gestures in a brief training session seems to be hold out promise as a way to improve children's narrative discourse performances. If gestures are indeed an embodied way to highlight certain aspects of language, we suggest that actively involving sensory-motor perceptive and production processes through the use of beats is likely to trigger an increase in attentional networks and thus benefit the coding of linguistic information.

\section{Acknowledgments}

We would like to express our gratitude to the Col-legi Dr. Masmitjà and Escola Montjuïc in Girona for helping us to recruit participants for the present study as well as to the participating children themselves and their families. We are grateful to the psychology team at University of Chicago where some preliminary results where presented and in particular Prof. Susan Goldin-Meadow and Dr. Özlem Ece Demir-Lira. We are also grateful to the Prosodic Studies Group in Barcelona, where we presented the study. Special thanks to Joan Borràs-Comes for helping with the statistical analyses; to Alfonso Igualada, for helping with the experimental design; and to Judith Llanes-Coromina, for helping with data collection. Many thanks also go to Clara and Anna, the storytellers featured in our stimulus recordings and to all the audio-visual technicians at Universitat Pompeu Fabra for helping us with recording and editing. This study was approved by the ethics committee of the Universitat Pompeu Fabra, and benefited from funding awarded by the Spanish Ministry of Economy and Competitiveness (FFI2015-66533P) and by the Generalitat de Catalunya (2014 SGR 925) to the Prosodic Studies Group. The first author also acknowledges an FI grant from the Generalitat de Catalunya (ref. 2017FI_B_00297). 


\section{References}

[1] I. Vilà-Giménez, A. Igualada, and P. Prieto, “Observing storytellers who use rhythmic beat gestures improves children's narrative discourse performance," Developmental Psychology, under review.

[2] Ö. E. Demir, J. A. Fisher, S. Goldin-Meadow, and S. C. Levine, "Narrative processing in typically developing children and children with early unilateral brain injury: Seeing gesture matters," Developmental Psychology, vol. 50, no. 3, pp. 815$828,2014$.

[3] Ö. E. Demir, M. L. Rowe, G. Heller, S. Goldin-Meadow, and S. C. Levine, "Vocabulary, syntax, and narrative development in typically developing children and children with early unilateral brain injury: early parental talk about the "there-and-then" matters," Developmental Psychology, vol. 51, no. 2, pp. 161$175,2015$.

[4] I. Duinmeijer, J. de Jong, and A. Scheper, "Narrative abilities, memory and attention in children with a specific language impairment," International Journal of Language \& Communication Disorders, vol. 47, no. 5, pp. 542-555, 2012.

[5] Ö. E. Demir, S. C. Levine, and S. Goldin-Meadow, "Narrative skill in children with early unilateral brain injury: a possible limit to functional plasticity," Developmental Science, vol. 13, no. 4, pp. 636-647, 2010.

[6] Ö. E. Demir, S. C. Levine, and S. Goldin-Meadow, "A tale of two hands: children's early gesture use in narrative production predicts later narrative structure in speech," Journal of Child Language, vol. 42, no. 3, pp. 662-681, 2015.

[7] L. J. Stites and Ş. Özçalışkan, "Who Did What to Whom? Children Track Story Referents First in Gesture," Journal of Psycholinguistic Research, vol. 46, no. 4, pp. 1019-1032, 2017.

[8] R. Naremore, A. E. Densmore, and D. Harman, Language intervention with school age children: conversation, narrative and text. San Diego, CA: Singular Publishing Group, 1995.

[9] A. Applebee, The child's concept of story. Chicago, IL: Chicago Press, 1978

[10] J. M. Colletta, M. Guidetti, O. Caprici, C. Cristilli, Ö. E. Demir, R. Kunene-Nicolas, and S. C. Levine, "Effects of age and language on co-speech gesture production: an investigation of French, American, and Italian children's narratives," Journal of Child Language, vol. 42, no. 1, pp. 122-145, 2015.

[11] D. McNeill, Hand and Mind: What Gestures Reveal about Thought. Chicago: University of Chicago Press, 1992.

[12] S. Goldin-Meadow, S. Kim, and M. Singer, "What the teacher's hands tell the student's mind about math," Journal of Educational Psychology, vol. 91, no. 4, pp. 720-730, 1999.

[13] W. C. So, C. S. Chen-Hui, and J. L. Wei-Shan, "Mnemonic effect of iconic gesture and beat gesture in adults and children: Is meaning in gesture important for memory recall?" Language and Cognitive Processes, vol. 27, no. 5, pp. 665-681, 2012.

[14] E. Austin and N. Sweller, "Presentation and production: The role of gesture in spatial communication," Journal of Experimental Child Psychology, vol. 122, no. 1, pp. 92-103, 2014.

[15] A. Igualada, N. Esteve-Gibert, and P. Prieto, "Beat gestures improve word recall in 3- to 5-year-old children," Journal of Experimental Child Psychology, vol. 156, pp. 99-112, 2017.

[16] J. Llanes-Coromina, I. Vilà-Giménez, O. Kushch, J. BorràsComes, and P. Prieto, "Beat gestures help preschoolers recall and comprehend discourse information," Journal of Experimental Child Psychology, in press, 2018.

[17] A. Macoun and N. Sweller, "Listening and watching: The effects of observing gesture on preschoolers' narrative comprehension," Cognitive Development, vol. 40, pp. 68-81, 2016.

[18] A. Yeo, I. Ledesma, M. J. Nathan, M. W. Alibali, and R. B. Church, "Teachers' gestures and students' learning: sometimes "hands off" is better," Cognitive Research: Principles and Implications, vol. 2, no. 1, pp. 41, 2017.

[19] C. E. Byrd, N. M. McNeil, S. K. D'Mello, and S. W. Cook, "Gesturing may not always make learning last," Proceedings of the $36^{\text {th }}$ Annual Conference of the Cognitive Science Society, pp. 1982-1987, 2014

[20] S. W. Cook, Z. Mitchell, and S. Goldin-Meadow, "Gesturing makes learning last," Cognition, vol. 106, no. 2, pp. 1047-1058, 2008.

[21] S. Goldin-Meadow, S. W. Cook, and Z. A. Mitchell, "Gesturing gives children new ideas about math," Psychological Science, vol. 20, no. 3, pp. 267-272, 2009.

[22] S. C. Broaders, S. W. Cook, Z. Mitchell, and S. GoldinMeadow, "Making children gesture brings out implicit knowledge and leads to learning," Journal of Experimental Psychology: General, vol. 136, no. 4, pp. 539-550, 2007.

[23] M. A. Novack, E. L. Congdon, N. Hemani-Lopez, and S. Goldin-Meadow, "From action to abstraction: Using the hands to learn math," Psychological Science, vol. 25, no. 4, pp. 903-910, 2014.

[24] M. W. Alibali, R. C. Spencer, L. Knox, and S. Kita, "Spontaneous gestures influence strategy choices in problem solving," Psychological Science, vol. 22, no. 9, pp. 1138-1144, 2011.

[25] M. W. Alibali and S. Kita, "Gesture highlights perceptually present information for speakers," Gesture, vol. 10, no. 1, pp. $3-$ $28,2010$.

[26] S. Goldin-Meadow and M. W. Alibali, "Gesture's role in speaking, learning, and creating language," Annual Review of Psychology, vol. 64, 257-283, 2013.

[27] E. Kirk and C. Lewis, "Gesture Facilitates Children's Creative Thinking," Psychological Science, vol. 28, no. 2, pp. 225-232, 2017.

[28] C. Lucero, H. Zaharchuk, and D. Casasanto, "Beat gestures facilitate speech production," Proceedings of the $36^{\text {th }}$ Annual Conference of the Cognitive Science Society, pp. 898-903, 2014.

[29] S. Shattuck-Hufnagel, A. Ren, M. Mathew, I. Yuen, and K. Demuth, "Non-referential gestures in adult and child speech: Are they prosodic?," Proceedings of the International Conference on Speech Prosody, pp. 836-839, 2016.

[30] D. Dimitrova, M. Chu, L. Wang, A. Özyürek, and P. Hagoort, "Beat that word: how listeners integrate beat gesture and focus in multimodal speech discourse," Journal of Cognitive Neuroscience, vol. 28, no. 9, pp. 1255-1269, 2016.

[31] A. Kendon, "Gestures as illocutionary and discourse structure markers in Southern Italian conversation," Journal of Pragmatics, vol. 23, no. 3, pp. 247-279, 1995.

[32] A. Kendon, Gesture: Visible Action as Utterance. Cambridge: Cambridge University Press, 2004.

[33] L. Bosch and N. Sebastián-Galles, "Evidence of Early Language Discrimination Abilities in Infants from Bilingual Environments," Infancy, vol. 2, no. 1, 29-49, 2001.

[34] M. W. Alibali, J. L. Evans, A. B. Hostetter, K. Ryan, and E. Mainela-Arnold, "Gesture-speech integration in narrative: Are children less redundant than adults?," Gesture, vol. 9, no. 3, pp. 290-311, 2009.

[35] N. L. Stein and C. G. Glenn, An analysis of story comprehension in elementary children. Norwood, NJ: Ablex, 1979.

[36] M. G. O’Brien, "L2 Learners' Assessments of Accentedness, Fluency, and Comprehensibility of Native and Nonnative German Speech," Language Learning, vol. 64, no. 4, pp. 715$748,2014$.

[37] T. Isaacs and P. Trofimovich, "Phonological memory, attention control, and musical ability: Effects of individual differences on rater judgments of second language speech," Applied Psycholinguistics, vol. 32, no. 1, pp. 113-140, 2011.

[38] S. Kennedy and P. Trofimovich, "Intelligibility, comprehensibility and accentedness of L2 speech: The role of listener experience and semantic context," Canadian Modern Language Review, vol. 64, no. 3, pp. 459-489, 2008.

[39] B. West, K. B. Welch, and A. T. Galecki, Linear mixed models: A practical guide using statistical software. New York: Chapman \& Hall/CRC

[40] E. Biau and S. Soto-Faraco, "Beat gestures modulate auditory integration in speech perception," Brain \& Language, vol. 124, no. 2, pp. 143-152, 2013. 